\title{
DISTRIBUTION AND METABOLIC FATE OF RADIOACTIVE CARBON FROM L-[U-14C]ARGININE ADMINISTERED INTO MICE
}

\author{
HIDEYUKI GOTO \\ Department of Anatomy, Osaka Medical College, Takatsuki, Osaka 569
}

Received for publication January 17, 1989 and in revised form March 29, 1989

\begin{abstract}
Tissue and organ distribution of radioactive carbon from ${ }^{14} \mathrm{C}$-labeled arginine in the mouse was studied by whole-body autoradiography and biochemical analysis. The mice injected intravenously with $\mathrm{L}-\left[\mathrm{U}-{ }^{14} \mathrm{C}\right]$ arginine were sacrificed at various intervals. Examination of autoradiographs disclosed that the injected ${ }^{14} \mathrm{C}$-arginine was rapidly taken up from the blood by the organs. The radioactivity in the pancreas was the highest throughout the intervals after injection in this investigation. The general pattern of the autoradiographs obtained after injection of radioactive arginine had a resemblance to those reported about other amino acids.

The comparative values among radioactivity in various organs estimated by a liquid scintillation counter were consistent with those obtained from whole-body autoradiographs. Radioactivity in the acid-insoluble fractions was increased with time in all organs examined. High-performance liquid chromatography of the acid-soluble fractions disclosed that several radioactive substances were detected in the examined organs soon after injection and that the amounts of the radioactive arginine and its metabolites and/or their molar ratios were different among the organs.
\end{abstract}

Arginine is distributed in tissues and body fluids in a free form and incorporated into protein molecules. Apart from its role in protein synthesis, arginine is a precursor of urea, creatine and other guanidine derivatives $(2,22)$. After the discovery of the urea cycle and the gradual elucidation of the enzymatic pathways in liver, kidney and in a variety of other organs for the synthesis of arginine (22), it has generally been assumed that arginine is dispensable in adult mammals because within the urea cycle they can make arginine (23). The distribution and metabolic fates of arginine have been extensively studied, but not satisfactorily in the whole body. The fate of the circulating arginine remains unknown. In the meantime, whole-body autoradiography, first developed by Ullberg (27), has been used for investigation of the distributions of hexoses $(14,25)$ and hexosamines $(10,11)$ in mice in our laboratory. In addition, using different post-injection times, the change in distribution with time can be followed. The distributions of methionine (1), glutamine (3), tryptophan (8), tyrosine (9) and other amino acids $(12,16)$ have been studied by this technique. The present report deals with the tissue distribution in mice by means of whole-body autoradiography and biochemical analysis at several intervals after intravenous injection of $\mathrm{L}-\left[\mathrm{U}-{ }^{14} \mathrm{C}\right]$ arginine. 


\section{MATERIALS AND METHODS}

Animals. Adult male albino mice of ICR strain, weighing approx. $25 \mathrm{~g}$, were used.

Labeled compound. L- $\left[\mathrm{U}-{ }^{14} \mathrm{C}\right]$ arginine monohydrochloride (specific activity: $342 \mathrm{mCi} / \mathrm{mmol}$ ) was purchased from Amersham International plc, England. The substance was lyophilyzed and reconstituted at a concentration of $50 \mu \mathrm{Ci} / \mathrm{ml}$ in physiological saline.

Whole-body autoradiography. The mice were injected intravenously with $10 \mu \mathrm{Ci}$ of radioactive arginine and sacrificed in groups of three at 5, 30,60 and $180 \mathrm{~min}$ after injection. Whole-body sagittal sections ( $25 \mu \mathrm{m}$ thick) of the mice were prepared according to the methods in a previous report (10). Autoradiography of sections was performed before and after incubation with $6 \%$ perchloric acid according to the manner reported by Shimada et al. (25). The autoradiographs of sections before and after the acid treatment were designated "untreated" and "treated" autoradiographs respectively. Some H-E stained sections were also prepared for tissue identification of autoradiographs (26). Densities of autoradiographs were measured with a microdensitometer (25).

Fractionation of organs. The mice were injected intravenously with $10 \mu \mathrm{Ci}$ of radioactive arginine and sacrificed in groups of two at 1, 5, 10 and $30 \mathrm{~min}$ after injection. The blood, brain, salivary gland, thymus, myocardium, skeletal muslce, stomach, small intestine, large intestine, liver, pancreas, spleen, kidney and testis were immediately removed. The acid-soluble, acid-insoluble and lipid fractions of each organ were obtained by the method described in a previous report (10). The radioactivity of each fraction was determined by a Packard liquid scintillation counter.

High-performance liquid chromatography (HPLC). The acid-soluble fractions obtained above were concentrated by using an evaporator and filtration through a $0.45-\mu \mathrm{m}$ mesh filter. A $100-\mu \mathrm{l}$ aliquot of the filtrate was injected into the HPLC (Gilson Model 302) with a $M$ \& $S$ Pack $C 18$ column ( $150 \mathrm{~mm} \times 4.6 \mathrm{~mm}$ i.d.). The mobile phase was $5 \mathrm{mM}$ sodium 1-heptanesulfonate and $1 \mathrm{mN} \mathrm{HCl}$. The flow rate was $1.0 \mathrm{ml} / \mathrm{min}$. Fractions of $0.2 \mathrm{ml}$ were collected and the radioactivity of each fraction was measured. The following materials were used as markers: arginine, urea, ornithine, citrulline, argininosuccinate, guanidinoacetic acid, guanidinosuccinic acid, creatine, phosphocreatine, creatinine, spermidine and spermine.

\section{RESULTS}

Whole-body autoradiography. After intravenous injection, the radioactive carbon from ${ }^{14} \mathrm{C}$-arginine was rapidly taken up from the blood by the tissues. Five min after injection, the highest radioactivity was observed in the pancreas, followed by the nasal mucosa, submandibular gland, small intestine, stomach (glandular part) and large intestine in decreasing order (Fig. 1a). All of the examined organs except the brain (cerebral cortex), lung and testis had higher radioactivity than the blood. The radioactivity in the organs except for the pancreas, sublingual gland and bone marrow was extensively reduced by perchloric acid treatment of sections (Fig. 1b). Thirty min after injection, the accumulation in the pancreas dominated the picture (Fig. 


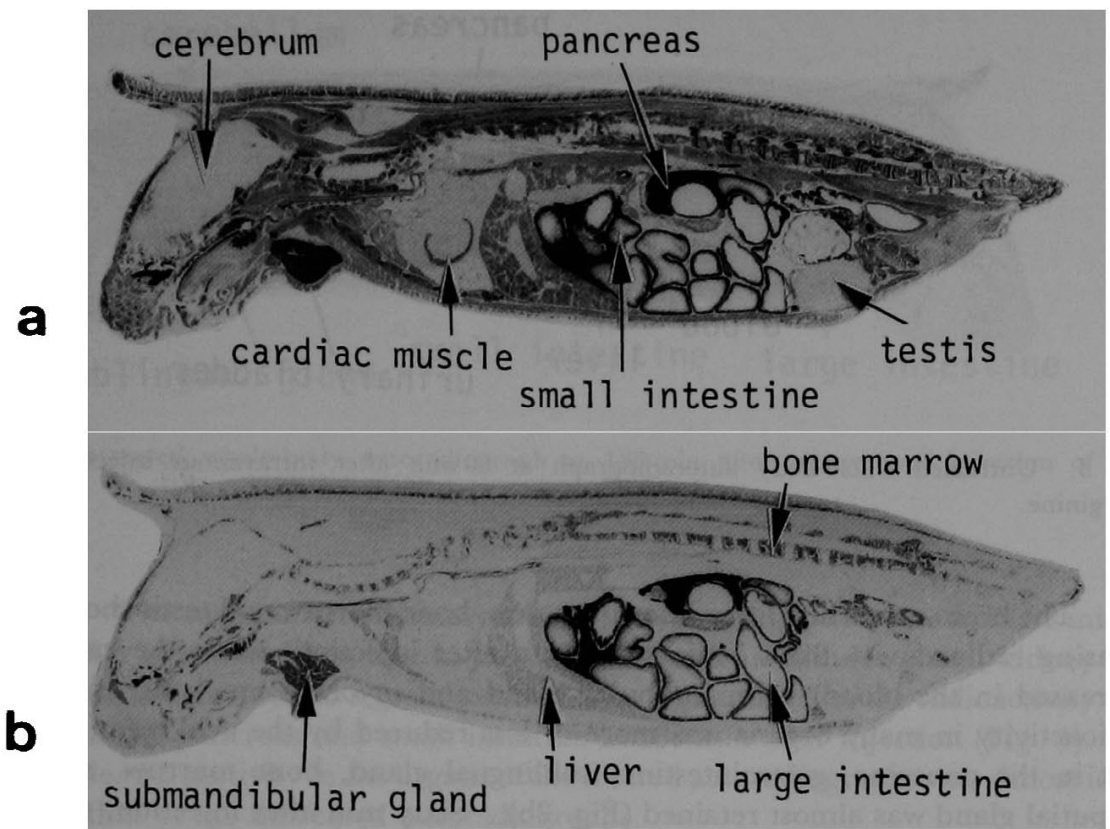

Fic. 1a, b. Whole-body autoradiographs at $5 \mathrm{~min}$ after intravenous injection of ${ }^{14} \mathrm{C}$-arginine. a, untreated. $\mathrm{b}$, treated with $6 \%$ perchloric acid.

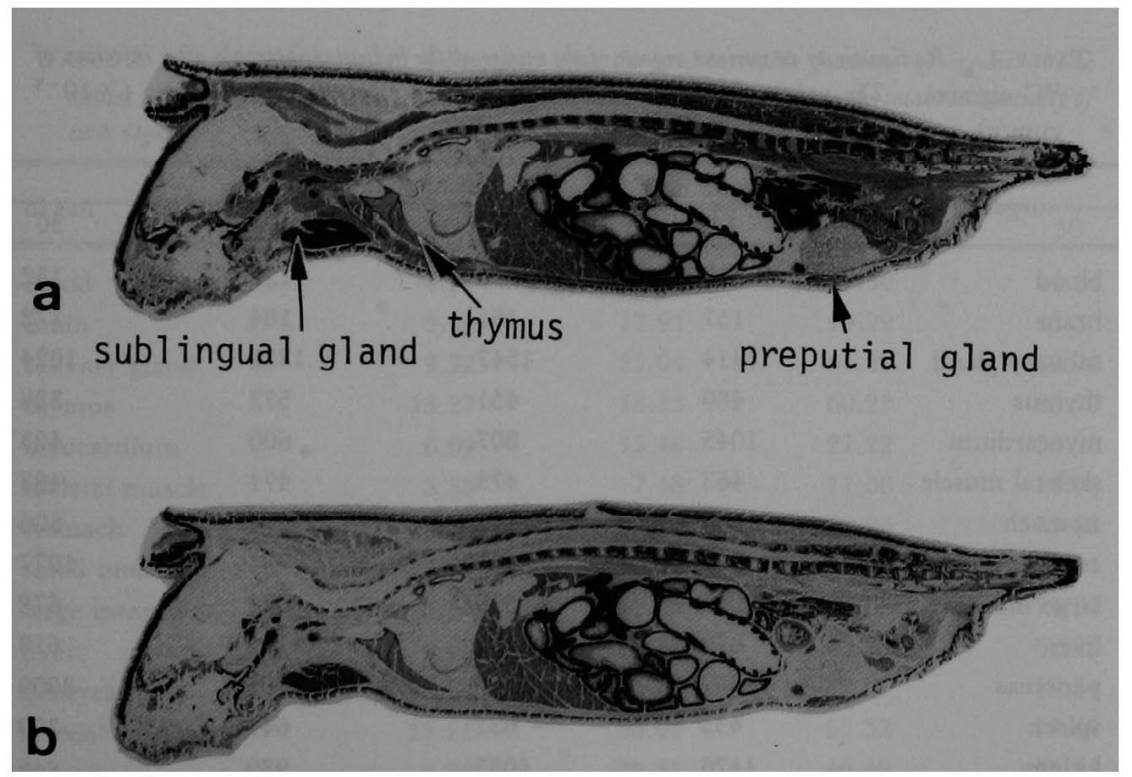

Fic. 2a, b. Whole-body autoradiographs at $30 \mathrm{~min}$ after intravenous injection of ${ }^{14} \mathrm{C}$-arginine. a, untreated. $\mathrm{b}$, treated with $6 \%$ perchloric acid. 


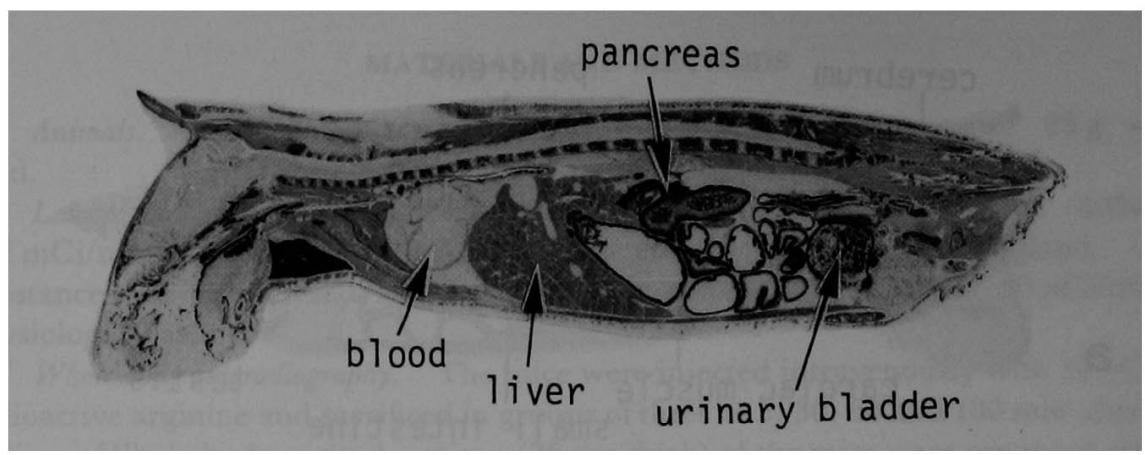

FIG. 3. Untreated whole-body autoradiograph at $60 \mathrm{~min}$ after intravenous injection of ${ }^{14} \mathrm{C}$ arginine.

2a). The brain, small and large intestines, skin, bone marrow and testis showed an increasing radioactivity from $5 \mathrm{~min}$ to $30 \mathrm{~min}$ after injection, while the radioactivity decreased in the blood, submandibular gland and myocardium. At this time the radioactivity in many organs was more or less reduced by the acid treatment while that in the pancreas, gastrointestine, sublingual gland, bone marrow, spleen and preputial gland was almost retained (Fig. $2 b$ ). Sixty min after injection, the highest radioactivity was observed in the pancreas (Fig. 3). From $30 \mathrm{~min}$ to $60 \mathrm{~min}$ after injection, the radioactivity increased in the brain, sublingual gland, thymus and spleen, while it decreased in the skeletal muscle and kidney. The radioactivity in the organs except for the submandibular gland, liver and skeletal muscle was retained by the acid

TABLE 1. Radioactivity in various organs of the mouse at the indicated intervals after injection of ${ }^{14} \mathrm{C}$-arginine. The values show the total radioactivity per wet weight of organs $\left(\times 10^{-3}\right.$ cpm/g).

\begin{tabular}{lrrrr}
\hline \multirow{2}{*}{ organ } & \multicolumn{4}{c}{ min after injection } \\
\cline { 2 - 5 } blood & 1 & 5 & 10 & 30 \\
brain & 657 & 296 & 150 & 152 \\
salivary gland & 157 & 151 & 184 & 172 \\
thymus & 1414 & 1547 & 1352 & 1024 \\
myocardium & 480 & 451 & 573 & 338 \\
skeletal muscle & 1045 & 807 & 600 & 423 \\
stomach & 463 & 475 & 471 & 483 \\
small intestine & 892 & 723 & 674 & 626 \\
large intestine & 999 & 800 & 794 & 1077 \\
liver & 947 & 599 & 528 & 678 \\
pancreas & 872 & 671 & 702 & 610 \\
spleen & 2362 & 2370 & 3465 & 3909 \\
kidney & 435 & 632 & 641 & 709 \\
testis & 1470 & 1035 & 989 & 846 \\
\hline
\end{tabular}




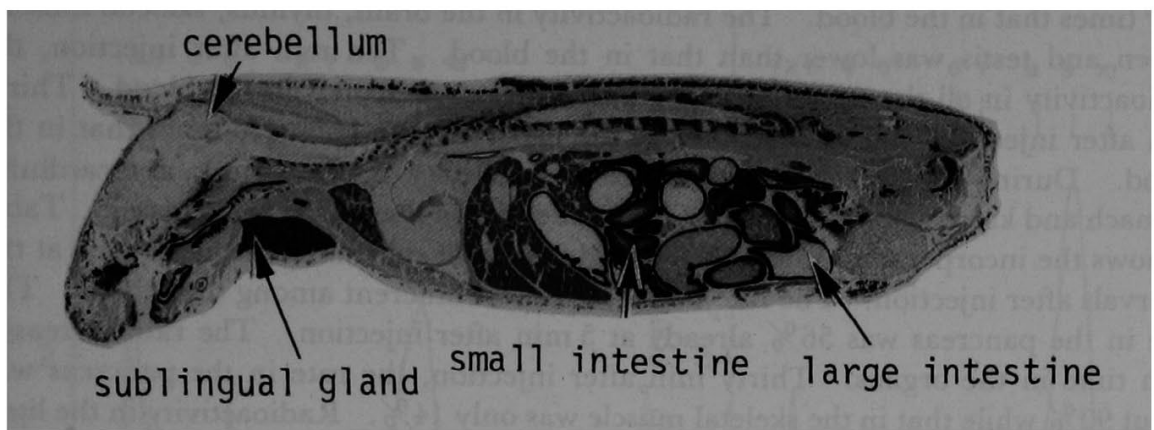

Fig. 4. Untreated whole-body autoradiograph at $180 \mathrm{~min}$ after intravenous injection of ${ }^{14} \mathrm{C}$ arginine.

treatment. The radioactivity in many organs showed a slight decrease from $60 \mathrm{~min}$ to 180 min after injection when that in the pancreas, submandibular gland, kidney and skeletal muscle decreased to a great extent. The highest level of the radioactivity was observed in the pancreas and small intestine at $180 \mathrm{~min}$ after injection (Fig. 4). At this time the radioactivity in the organs of the treated autoradiographs was almost identical with that of the untreated autoradiographs.

Fractionation of organs. Organ samples obtained from the mice given ${ }^{14} \mathrm{C}$-arginine injection were fractionated into the acid-soluble, acid-insoluble and lipid fractions. Table 1 shows the total radioactivity of the organs at the examined intervals after injection. One min after injection, the radioactivity in the pancreas was the highest and

TABLE 2 Incorporation rate of radioactivity into the acid-insoluble fractions of organs. The values represent per cent of the radioactivity in the acid-insoluble fraction to the total radioactivity of each organ.

\begin{tabular}{lrrrr}
\hline \multirow{2}{*}{ organ } & \multicolumn{4}{c}{ min after injection } \\
\cline { 2 - 4 } blood & \multicolumn{1}{c}{5} & 10 & 30 \\
brain & 6.91 & 7.01 & 7.30 & 41.61 \\
salivary gland & 5.50 & 12.91 & 19.99 & 43.30 \\
thymus & 9.32 & 23.04 & 41.89 & 60.76 \\
myocardium & 13.27 & 18.73 & 60.27 & 60.77 \\
skeletal muscle & 6.09 & 15.48 & 27.22 & 58.26 \\
stomach & 3.33 & 7.48 & 11.00 & 14.08 \\
small intestine & 13.38 & 44.52 & 59.96 & 75.63 \\
large intestine & 12.49 & 48.08 & 57.54 & 69.01 \\
liver & 13.58 & 46.23 & 60.66 & 74.91 \\
pancreas & 6.03 & 23.58 & 40.23 & 62.29 \\
spleen & 25.28 & 56.19 & 72.67 & 89.34 \\
kidney & 13.71 & 50.01 & 63.52 & 77.49 \\
testis & 9.30 & 26.81 & 40.49 & 45.71 \\
& 6.76 & 16.72 & 19.89 & 45.43 \\
\hline
\end{tabular}


four times that in the blood. The radioactivity in the brain, thymus, skeletal muscle, spleen and testis was lower than that in the blood. Ten min after injection, the radioactivity in all the organs examined was higher than that in the blood. Thirty min after injection, the radioactivity in the pancreas was about 26 times that in the blood. During the intervals tested, the radioactivity in the blood, myocardium, stomach and kidney decreased with time, while that in the pancreas increased. Table 2 shows the incorporation rate into the acid-insoluble substances in the organs at the intervals after injection. The rate was more or less different among the organs. The rate in the pancreas was $56 \%$ already at $5 \mathrm{~min}$ after injection. The rate increased with time in the organs. Thirty min after injection, the rate in the pancreas was about $90 \%$ while that in the skeletal muscle was only $14 \%$. Radioactivity in the lipid fractions of the organs at any examined interval after injection did not exceed $1 \%$ of their total radioactivity.

HPLC. Figure 5 shows the chromatograms by the HPLC separation of the acidsoluble fractions. As shown in Fig. 5a, the blood had the radioactivity for urea, guanidinosuccinic acid and arginine at $1 \mathrm{~min}$ after injection. The radioactivity was also observed in the fractions corresponding to argininosuccinate and ornithine. The amounts of these radioactive substances decreased with time. These radioactive substances were detected in the liver, salivary gland, stomach and large intestine at $1 \mathrm{~min}$ after injection (Figs. 5b-e), although the molar ratios of the radioactive substances were different among the organs. The radioactive arginine was not detected in the stomach at $5 \mathrm{~min}$ after injection. In the large intestine, the relative amount of radioactive urea was smaller than that in the organs examined. The small intestine had the radioactivity for guanidinoacetic acid in addition to that for the substances stated above at $1 \mathrm{~min}$ after injection (Fig. 5f). This organ had the radioactivity for urea, citrulline and guanidinosuccinic acid at $30 \mathrm{~min}$ after injection. The kidney had the principal peaks of the radioactivity corresponding to urea, guanidinosuccinic acid, creatine and arginine at $1 \mathrm{~min}$ after injection (Fig. $5 \mathrm{~g}$ ). At $30 \mathrm{~min}$ after injection, the radioactivity was observed almost only in the fraction corresponding to urea. The pancreas had the the radioactivity for urea, creatine, guanidinoacetic acid and arginine at $1 \mathrm{~min}$ after injection (Fig. $5 \mathrm{~h}$ ). The radioactivity for guanidinosuccinic acid appeared at $5 \mathrm{~min}$ after injection. The significant radioactivity for spermine, spermidine (17 min of the retention time) and creatinine ( $21 \mathrm{~min}$ of the retention time) was not detected in any of the organs at any intervals after injection.

\section{DISCUSSION}

The distribution of radioactive carbon from ${ }^{14} \mathrm{C}$-arginine was demonstrated by whole-body autoradiography and biochemical experiments. A rapid incorporation of exogenously administered ${ }^{14} \mathrm{C}$-arginine into the various organs was consistent with

Fig. 5. HPLC of the acid-soluble fractions of the blood (a), liver (b), salivary gland (c), stomach (d), large intestine (e), small intestine (f), kidney (g) and pancreas (h). (-) 1 min after injection, (-.-.): $5 \mathrm{~min}$ after injection, (-): $10 \mathrm{~min}$ after injection, (-....): 30 min after injection. Bars indicate the retention time of standards: 1, phosphocreatine; 2, urea; 3, argininosuccinate; 4, citrulline; 5 , guanidinosuccinic acid; 6 , creatine; 7 , guanidinoacetic acid; 8 , ornithine; 9 , arginine; 10 , spermine. 


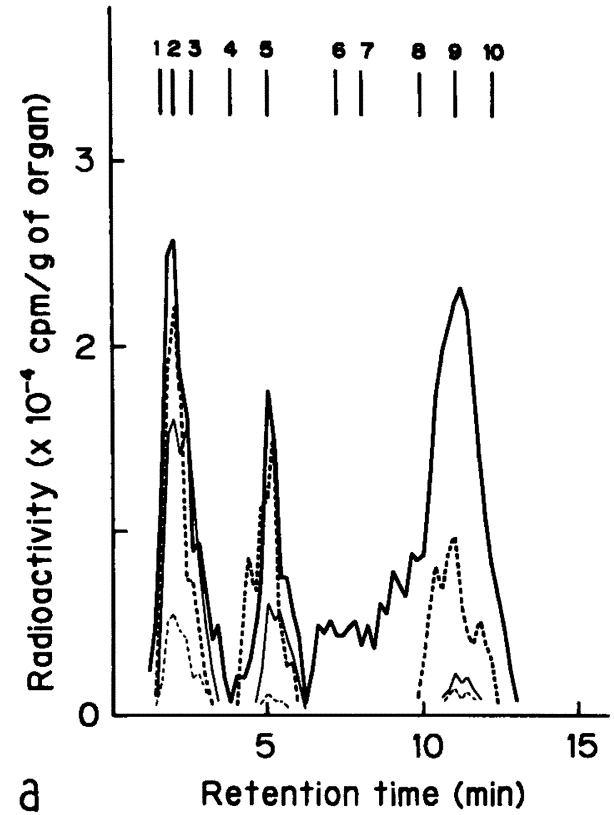

Fic. 5a.

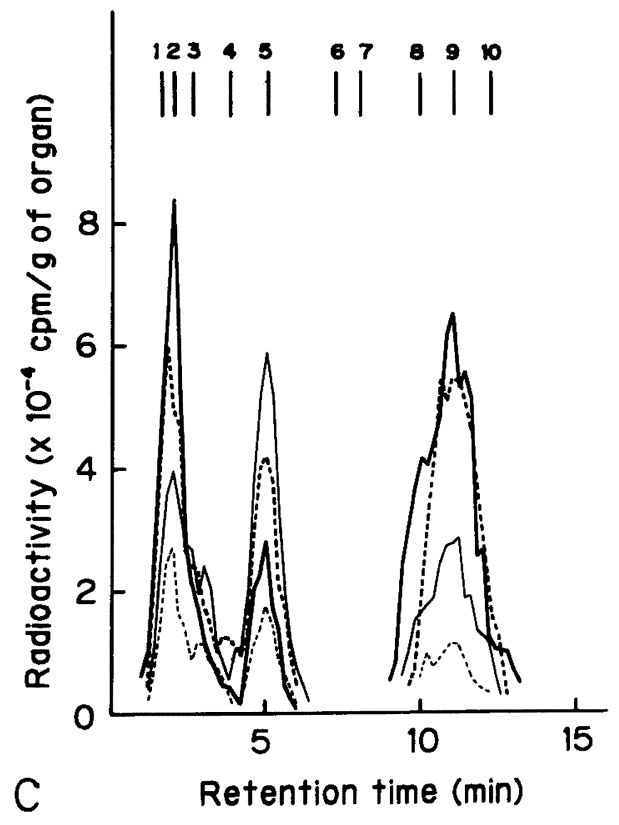

Fic. 5c.

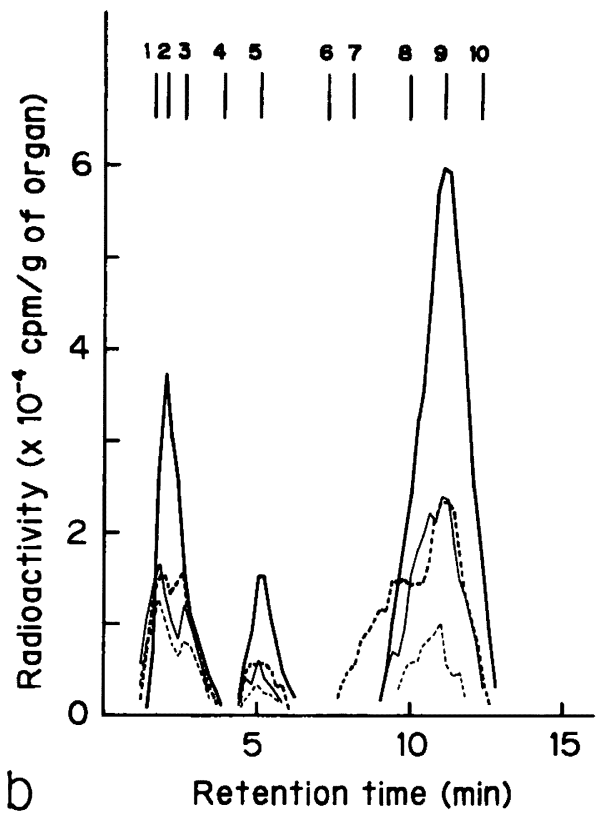

Fig. 5b.

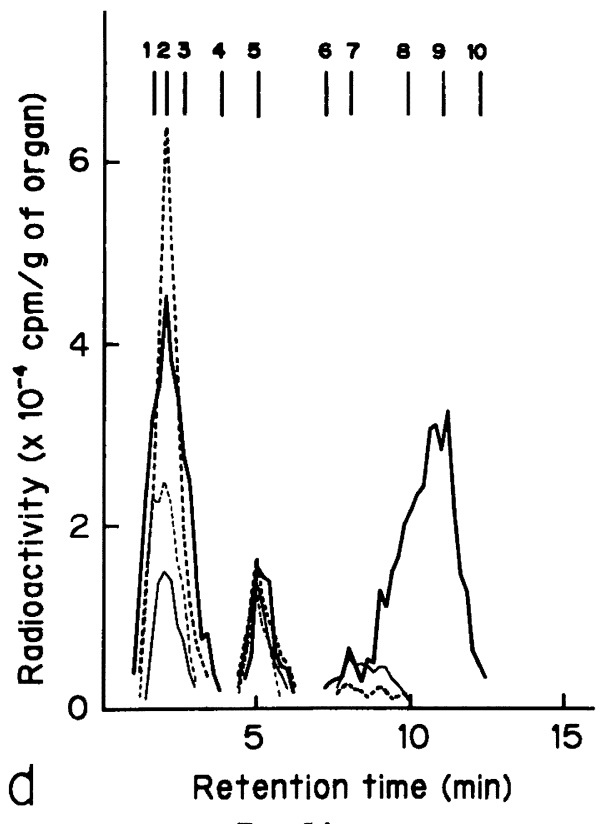

FIG. 5d. 


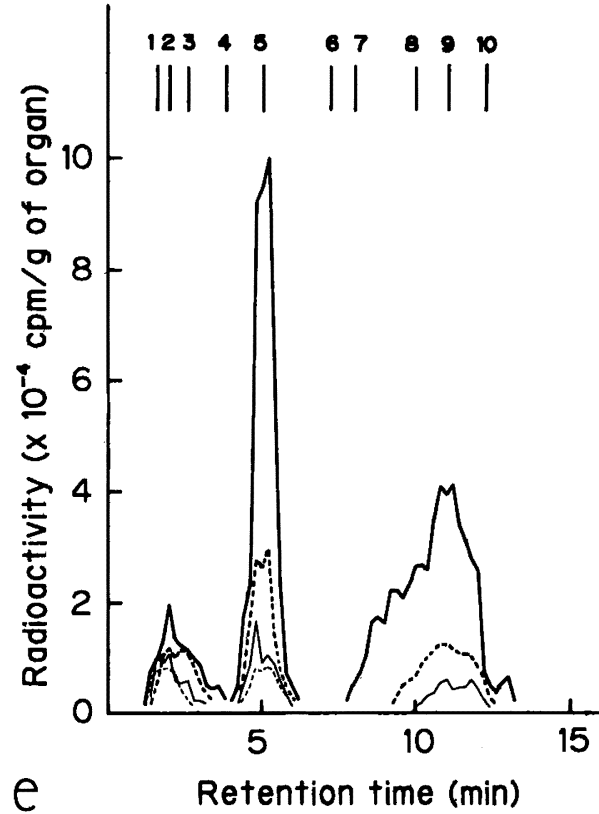

Fig. $5 e$.

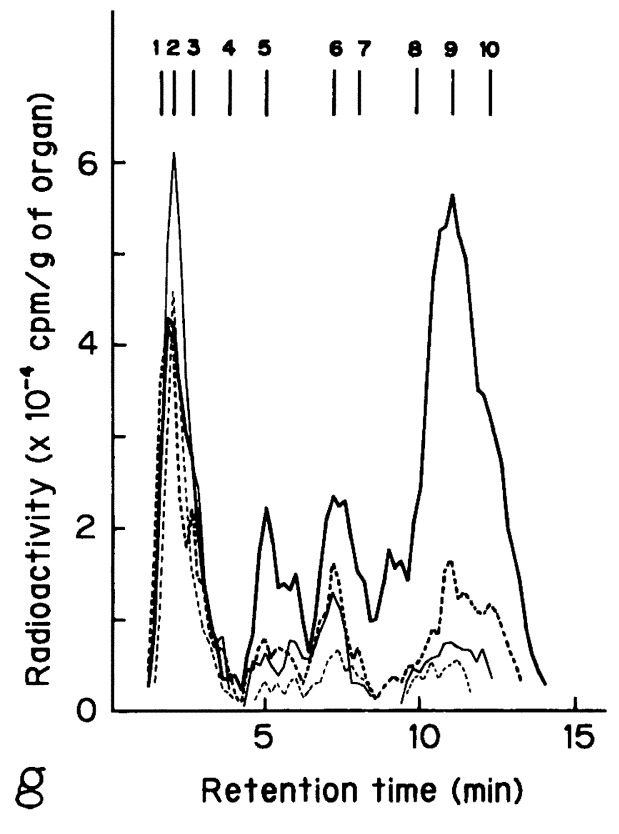

Fig. 5g.

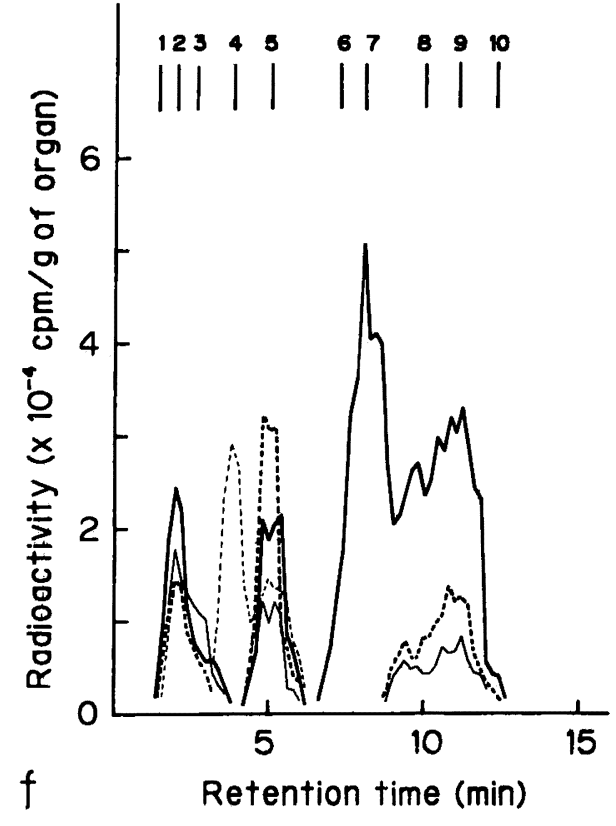

Fig. 5f.

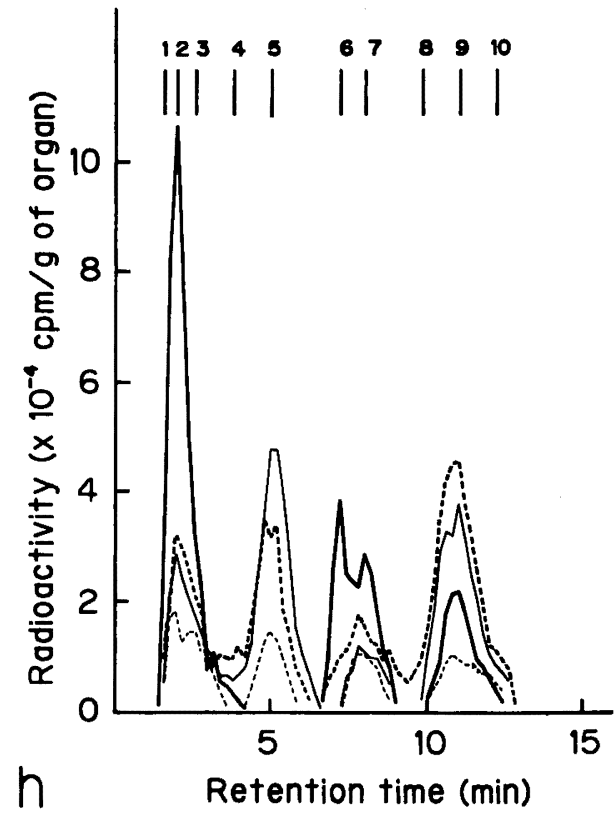

Fig. 5h. 
other amino acids reported $(3,8,9)$. The findings on the brain and testis at an early time after injection indicate that it is difficult for arginine to be incorporated into these organs and may reflect the concepts of the blood-brain barrier (18) and the blood-testis barrier (5).

The advantages of the treated autoradiographs for estimating the radioactivity in the acid-insoluble substances in the organs have been discussed previously (8). In this case, radioactive acid-insoluble substances are thought to be responsible for proteins. In general, the highest uptake of injected amino acids takes place in organs with a rapid protein synthesis such as the pancreas, gastrointestinal mucosa, bone marrow and lymphatic tissues (12). The findings at $5 \mathrm{~min}$ after injection, as shown in Figs. 1a and $b$, indicate that a rapid protein synthesis occurs in the pancreas, sublingual gland and bone marrow. The finding at $180 \mathrm{~min}$ after injection indicates that most of the radioactive substances remained as proteins in the organs at this time. This finding that the pancreas had the highest radioactivity during the intervals tested is consistent with other reports about glutamine (3), tryptophan (8) and tyrosine (9), and different from those about methionine (1) and aspartic acid (16). This may imply the differences of the pool size of amino acids and/or the requirement for protein synthesis in the pancreas. In this investigation, most of the radioactivity in the pancreas may be responsible for that in the exocrine part of this organ, as several investigators $(3,12)$ reported that there was a high concentration of radioactivity in the exocrine part of this organ but little or no radioactivity in the islands of Langerhans. The general pattern of the autoradiographs obtained after injection of radioactive arginine had a resemblance to those reported about tryptophan $(8)$ and other amino acids $(9,12,16)$, and was different from those about hexoses $(14,25)$ and hexosamines $(10,11)$.

The mice were sacrificed soon after injection of radioactive metabolites in the acid-soluble fractions by means of biochemical experiments, as Rogers et al. (24) estimated the circulating half-life of arginine in the rat to be 3-6 min. With regard to the radioactivity in the organs at $5 \mathrm{~min}$ and $30 \mathrm{~min}$ after injection, the results shown in Table 1 are approximately consistent with those obtained by whole-body autoradiography stated above. The findings that the radioactivity in the blood and kidney decreased with time are coincident with those about tryptophan (8) and tyrosine (9) and indicate that the radioactive substances in the blood are rapidly taken up by the tissues and/or excreted in the urine.

The values shown in Table 2 were lower than those estimated by whole-body autoradiography. This discrepancy seems to depend upon the two different methods as discussed in a previous report (8). A rapid increase of the incorporation rate in the blood from $10 \mathrm{~min}$ to $30 \mathrm{~min}$ after injection may be attributed to the supply of the blood proteins produced in the liver. The values of the skeletal muscle in Table 2 indicate that most of the radioactive substances remain as acid-soluble forms in this organ, and imply that the rate of protein synthesis in this organ is low or that arginine and its metabolites are difficult to be excreted from this organ.

HPLC has been used for the analysis of arginine and its metabolites $(15,19,20)$. The HPLC examination of the acid-soluble substances demonstrated that the distribution of radioactive acid-soluble substances depend on the organs and the intervals after injection. These findings perhaps reflect the different levels of the enzymes participating in the metabolism of arginine by the organs. $(13,22)$. That the radioactivity for guanidinoacetic acid was observed in the kidney, pancreas and small intestine 
supports that the enzyme catalyzing the formation of guanidinoacetic acid from arginine is present only in the kidney and pancreas of rats (7), and implies the possibility that the enzyme is also present in the small intestine of mice. The results by HPLC showed that urea and guanidinosuccinic acid were the principal metabolites in the organs examined. Guanidinosuccinic acid, has been detected in the liver of uremia rats (21) and in the liver and kidney of normal rats $(19,20)$, is formed from transamidination of arginine to aspartic acid (20). On the other hand, the interorgan flow of arginine is an important issue in relation to the urea cycle and critical nature of the extrahepatic economy (4). The high concentration of arginase in the liver prevents the release of arginine into general circulation (17). Arginine synthesis from citrulline occurs in vivo in the kidney (6), which has a lower concentration of arginase than the liver (22). The kidney itself cannot form citrulline due to a lack of ornithine carbomoyltransferase $(7,13)$. Citrulline is primarily produced in the small intestine $(13,28)$, and supplied by this organ (13). As stated above, the organ interrelation of arginine metabolism has been discussed, but involves many problems to be solved. Investigations by whole-body autoradiography and biochemical analysis, as described in this report, after administration of radioactive substances such as ornithine and citrulline may be useful for resolving them.

\section{ACKNOWLEDGMENT}

This work was supported in part by a Grant-in-Aid for Scientific Research from the Ministry of Education, Science and Culture, the Japanese Government (General Research B, No. 60480102).

\section{REFERENCES}

1. Benard, P. and Durand, S.: Distribution of radioactivity in rats injected with $\mathrm{L}^{-14} \mathrm{C}$ methionine as studied by whole body autoradiography. Ann. Rech. Vet. 11; 201-208, 1980.

2. Bender, D. A.: Amino Acid Metabolism, 2nd ed., John Wiley \& Sons, Inc., New York, 1985, pp. 119-145.

3. Cassano, G. B. and Hansson, E.: Uptake of $\left[{ }^{14} \mathrm{C}\right]$ glutamine in the tissues of the mouse studied by whole-body autoradiography. J. Neurochem. 12; 851-855, 1965.

4. Christensen, H. N.: Interorgan amino acid nutrition. Physiol. Rev. 62; 1193-1233, 1982.

5. Dym, M. and Caviccha, J.: Further observations on the blood testis barrier in monkeys. Biol. Reprod. 17; 390-403, 1977.

6. Featherston, W. R., Rogers, Q. R. and Freeland, R. A.: Relative importance of kidney and liver in synthesis of arginine by the rat. Am. J. Physiol. 224; 127-129, 1973.

7. Funahashi, M., Kato, H., Shinosaka, S. and Nakagawa, H.: Formation of arginine and guanidinoacetic acid in the kidney in vivo. Their relations with the liver and their regulation. J. Biochem. 89; 1347-1356, 1981.

8. Goto, H., Matsushima, M., Kanayama, T. and Kihara, T.: The distribution of radioactive carbon from L-[side chain-3-- ${ }^{14}$ C]tryptophan in mice. Acta histochem. cytochem. 20; 427-436, 1987.

9. Goto, H., Matsushima, M., Kanayama, T. and Kihara, T.: The distribution of radioactive carbon from L-[U-14 C]tyrosine in mice. Acta histochem. cytochem. 20; 557-567, 1987.

10. Goto, H., Watanabe, M., Shimono, R. and Kihara, T.: The distribution of radioactive carbon from $\left[\mathrm{U}^{-14} \mathrm{C}\right]$ glucosamine in mice. Acta histochem. cytochem. 17; 213-222, 1984. 
11. Goto, H., Watanabe, M., Shimono, R. and Kihara, T.: The distribution of radioactive carbon from $\left[1-{ }^{14} \mathrm{C}\right]$ galactosamine in mice. Acta histochem. cytochem. 18; 165-173, 1985.

12. Hansson, E.: The formation of pancreatic juice proteins studied with labelled amino acids. $A c$ ta physiol. scad. 46 (supple 161); 1-99, 1959.

13. Jones, M. E.: Conversion of glutamate to ornithine and proline: pyrroline-5-carboxylate, a possible modulator of arginine requirements. J. Nutr. 115, 509-515, 1985.

14. Kihara, T., Goto, H., Kuno, N., Maruyama, T., Matsushima, M. and Shimono, R.: Distribution of ${ }^{14} \mathrm{C}$-labeled hexoses in mice studied by whole-body autoradiography (abstract). XII International Anatomical Congress 1985 (London), A355.

15. Marescau, B., Qureshi, I. A., Deyn, P. D., Letarte, J., Ryba, R. and Lowenthal, A.: Guanido compounds in plasma, urine and cerebrospinal fluid of hyperargininemic patients during therapy. Clin. Chim. Acta 146; 21-27, 1985.

16. Masuoka, D. T., Alcaraz, A. F., Cohen, M. B. and Spolter, L.: Acute distribution of ${ }^{14}$ Camino acids in mice as determined by whole-body autoradiography: adjunct for radiopharmaceutical synthesis. Int. J. Appl. Rad. Isot. 24; 705-707, 1973.

17. Morris, J. G.: Nutritional and metabolic responses to arginine defficiency in carnivores. $J$. Nutr. 114; 524-531, 1985.

18. Pardridge, W. M.: Brain metabolism: a perspective from the blood-brain barrier. Physiol. Rev. 63; 1481-1535, 1983.

19. Perez, G. O., Epstein, M., Rietberg, B. and Loutzenhiser, R.: Metabolism of arginine by the isolated perfused rat kidney. Am. J. Physiol. 235; F376-F380, 1978.

20. Perez, G., Rey, A. and Schiff, E.: The biosynthesis of guanidinosuccinic acid by perfused rat liver. J. Clin. Invest. 57; 807-809, 1976.

21. Perez, G., Riebtberg, B., Owens, B. and Shiff, E. R.: Effect of acute uremia on arginine metabolism and urea and guanidino acid production by perfused rat liver. Pflügers Arch. 372; 275-278, 1977.

22. Ratner, S.: Enzymes of arginine and urea synthesis. Adv. Enzymol. 39; 1-90, 1973.

23. Rogers, Q. R. and Visek, W. J.: Metabolic role of urea cycle intermediates: nutritional and clinical aspects. J. Nutr. 115; 505-508, 1985.

24. Rogers, Q. R., Freeland, R. A. and Symmons, R. A.: In vivo synthesis and utilization of argnine in the rat. Am. J. Physiol. 223; 236-240, 1972.

25. Shimada, M., Kihara, T., Watanabe, M. and Kurimoto, K.: The distribution of ${ }^{14} \mathrm{C}$ from [U$\left.{ }^{14} \mathrm{C}\right]$ glucose in mice using whole-body autoradiography. J. Histochem. Cytochem. 24; 591-600, 1976.

26. Shimono, R., Watanabe, M. and Goto, H.: A new method of preparation of whole-body autoradiography and staining. (in Japanese) Acta Anat. Nippon 57; 15-21, 1982.

27. Ullberg, S.: Studies on the distribution and fate of $\mathbf{S}^{35}$-labelled benzylpenicillin in the body. Acta radiol. (Stockh.) Suppl. 118; 1-110, 1954.

28. Windmueller, H. G. and Spaeth, A. E.: Source and fate of circulating citrulline. Am. J. Physiol. 241; E473-E480, 1981. 